\title{
Delivery Platform for Hydrophobic Drugs: Prodrug Approach Combined with Self-Assembled Multilayers
}

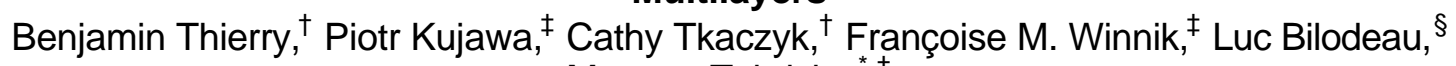
Maryam Tabrizian ${ }^{*}, \dagger$

Department of Biomedical Engineering, McGill university, H3A 2B; Faculté de Pharmacie and Département de Chimie, Université de Montréal, H3C 3J7; Montreal Heart Institute, HIT 1C8, Montreal, Canada

\section{Synthesis of Hyaluronan-paclitaxel bioconjugate (HA-Pac).}

Scheme 1. Synthetic procedure.

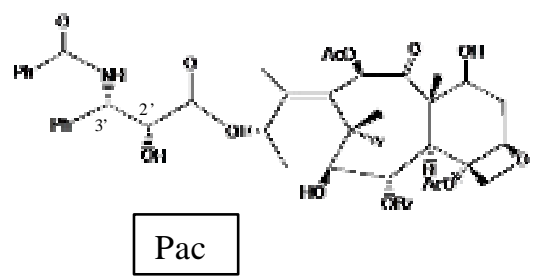

$\overrightarrow{\text { 1- Succinic anhydride, Pyridine }}$ 2- NHS, DCC

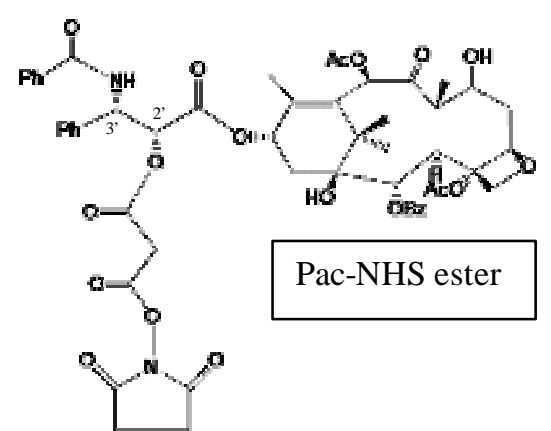

$\mathrm{H}_{2} \mathrm{O} / \mathrm{DMF}$

$\mathrm{HA}-\mathrm{NH}_{2}$

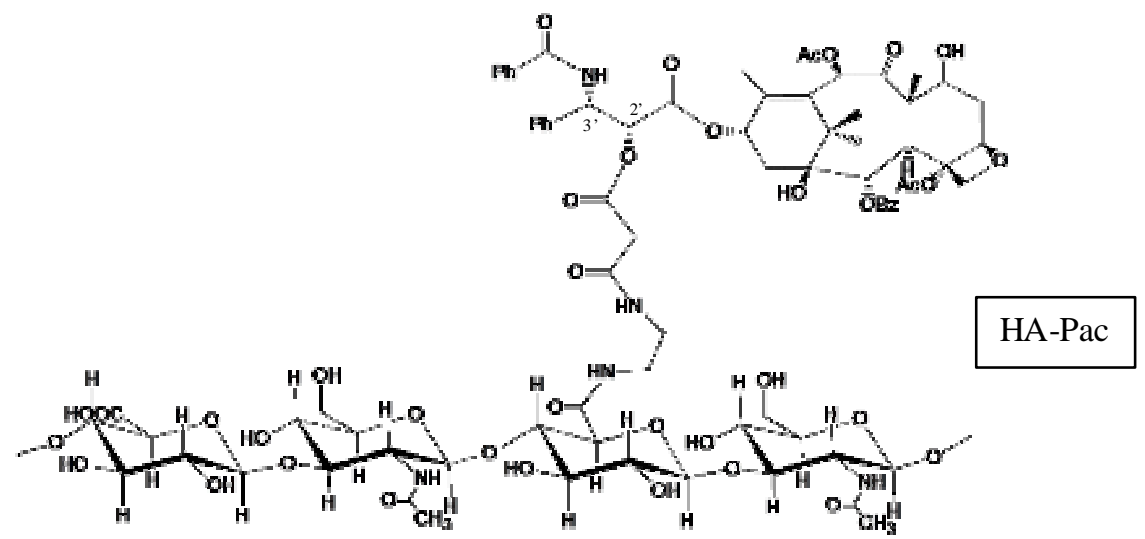

Preparation of HA-NH . Hyaluronan (HA) (Mw 500,000, gift of Hyal Pharmaceutical Corp) was used as received. Ethylenediamine hydrochloride (EDA:2HCl, Reaction 1: 0.3 eq. and reaction 2: 0.7 eq.) was added to a solution of 1-ethyl-3-(3-dimethylaminopropyl) carbodiimide (EDC, 1.3 eq.) and $\mathrm{HA}(200 \mathrm{mg})$ in MES buffer (0.1 M, pH 5.0). The reaction mixture was kept overnight at room temperature to yield $\left(\mathrm{HA}-\mathrm{NH}_{2}\right)$, which was purified by dialysis against water and recovered by freeze-drying. Yields: Reaction 1: 83\%; Reaction 2: $78.5 \%$. The presence of the ethylenediamine groups on the polymer was ascertained from the ${ }^{1} \mathrm{H}$ NMR spectrum of $\mathrm{HA}-\mathrm{NH}_{2}$, which presents a signal at $\delta 3.05 \mathrm{ppm}$, attributed to the ethylene protons of the ethylenediamine 
moieties. This signal, together with the singlet at $\delta 1.89 \mathrm{ppm}$ attributed to the acetamide methyl protons resonance, was used to estimate the degree of functionalization of $\mathrm{HA}-\mathrm{NH}_{2}: \mathrm{HA}^{-} \mathrm{NH}_{2}-1$ : $0.05 \mathrm{~mol}$ ethylene diamine groups/disaccharide units for $\mathrm{HA}-\mathrm{NH}_{2} ; \mathrm{HA}-\mathrm{NH}_{2}-2: 0.1$ mol ethylene diamine groups/disaccharide units for $\mathrm{HA}-\mathrm{NH}_{2}$.

Preparation of paclitaxe+NHS ester (Pac-NHS). Pac-NHS was prepared in two steps, esterification of the 2' hydroxyl group of Pac, followed by activation to the N-hydroxy-succinimide (NHS) ester, starting with $200 \mathrm{mg}$ of paclitaxel (BioxelPharma, Inc.) were dissolved with succinic anhydride (1.3 eq) in $9.5 \mathrm{~mL}$ of $\mathrm{CH}_{2} \mathrm{CL}_{2}$ at RT. $26 \mu \mathrm{L}$ (10-fold excess) of dry pyridine was added to the mixture and left for 3 days at RT. The mixture was concentrated in vacuo, then dissolved in 5 $\mathrm{mL}$ of $\mathrm{CH}_{2} \mathrm{CL}_{2}$ and purified on silica gel (wash with hexane and elute with ethyl acetate). Yields: $75.5 \%$. The activated ester was prepared by reacting paclitaxel-hemisuccinate and $\mathrm{N}$ hydroxysulfosuccinimide (NHS, 1.1 eq.) and dicyclohexylcarbodiimide (DCC, 1.1 eq.) in EtOAc for 2 days at RT. The precipitate (DC urea) was filtrated off. The success of the reaction was confirmed by ${ }^{1} \mathrm{H}$ NMR spectroscopy analysis. The ${ }^{1} \mathrm{H}$ NMR spectrum of the product (Figure S1) presents a signal at $2.6 \mathrm{ppm}$ attributed to the resonance of the succinimide methylene protons ($\left.\mathrm{CO}\left(\mathrm{CH}_{2}\right)_{2} \mathrm{CO}_{2}-\right)$ and signals at 5.49 and $5.97 \mathrm{ppm}$ due to the resonance of the protons linked to C-2' and C-3', respectively.

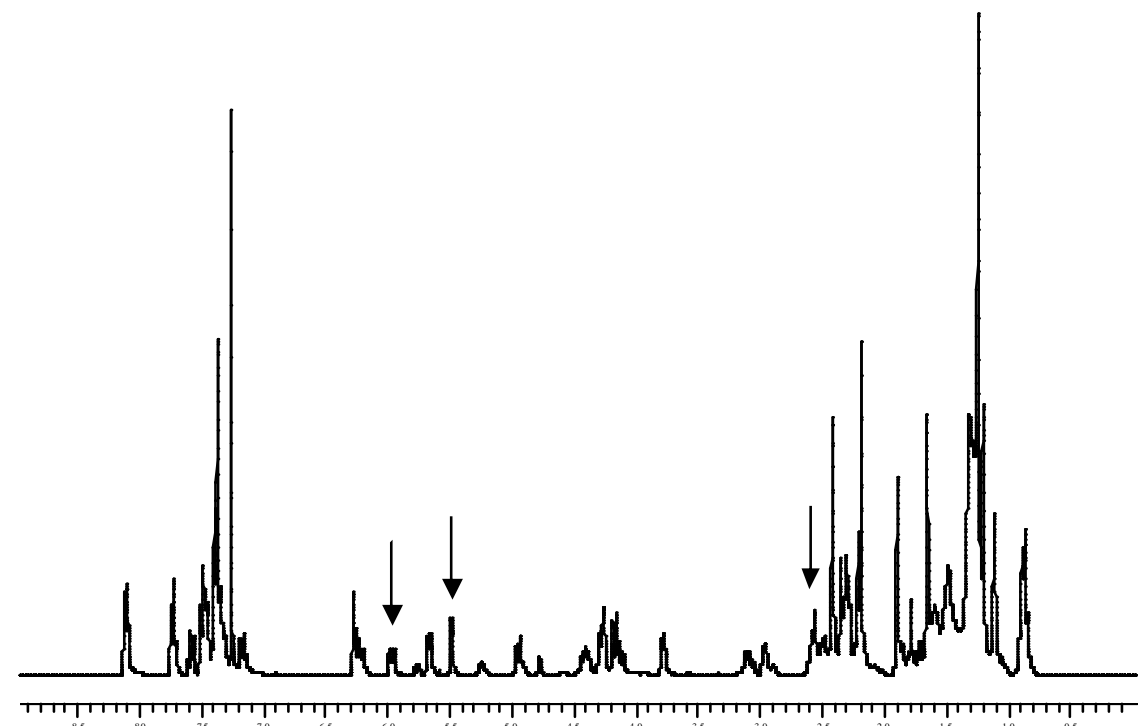

Figure S1. ${ }^{1} \mathrm{H}$ NMR of the NHS ester-2'-paclitaxel in $\mathrm{CDCl}_{3}$

Preparation of HA-Pac. The bioconjugate HA-Pac was prepared by reaction of Pac-NHS with

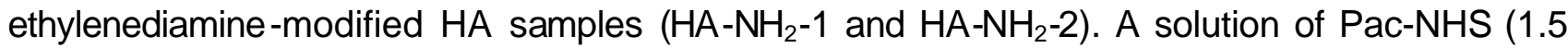
eq $/ \mathrm{NH}_{2}$ eq) in DMF was added to a solution $\mathrm{HA}-\mathrm{NH}_{2}(150 \mathrm{mg}, 3.7 \mathrm{mmol}$ disaccharide) in a phosphate buffer $(75 \mathrm{~mL}, 3.0 \mathrm{mM}, \mathrm{pH}$ 6.5). The mixture was kept for $24 \mathrm{~h}$ at RT. It was purified by dialysis, first against $50 \%$ acetone $/ \mathrm{H}_{2} \mathrm{O}$, to remove excess Pac-NHS, then against water $\mathrm{H}_{2} \mathrm{O}$ for $24 \mathrm{~h}$. The level of Pac conjugation was $3 \mathrm{~mol} \%$ and $6 \mathrm{~mol} \%$ per disaccharide units for reactions carried out with $\mathrm{HA}-\mathrm{NH}_{2}-1$ and $\mathrm{HA}-\mathrm{NH}_{2}-2$, respectively, as determined by UV absorbance spectroscopy analysis of HA-Pac solutions in 80:20 acetonitrile: $\mathrm{H}_{2} \mathrm{O}$, using Pac $\left(\varepsilon=2.8 \times 10^{4}\right.$, $?_{\max }=228 \mathrm{~nm}$ ) as reference. (Fig. S2) The HA-Pac sample with $6 \mathrm{~mol} \%$ Pac was insoluble in water or buffer solutions. It was not used in the construction of multilayers. 


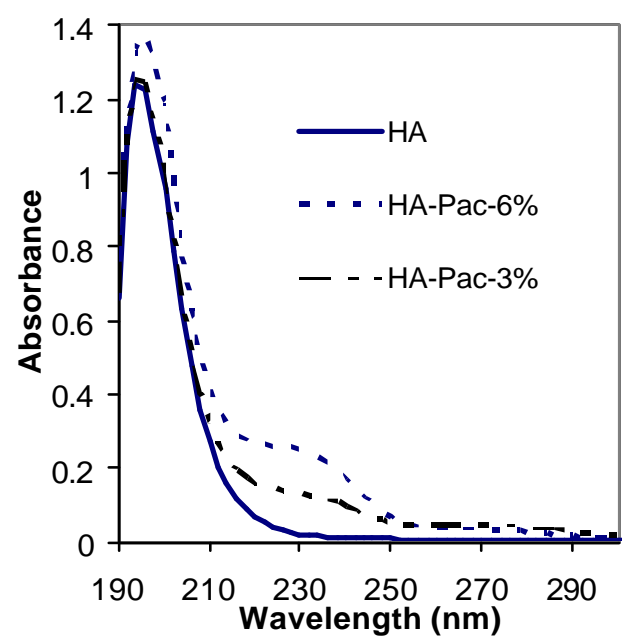

Figure S2. UV spectra of $\mathrm{HA}$ and two samples of HA-Pac in 80:20 acetonitrile: $\mathrm{H}_{2} \mathrm{O}$

\section{Synthesis of rhodamine-labeled chitosan (Rho-CH).}

Rhodamine-labeled chitosan was prepared following a procedure reported previously (Qaqish, R.B., Amiji, M.M., Synthesis of a fluorescent chitosan derivative and its application for the study of chitosan-mucin interactions, Carbohydr. Polym., 38, 99-107, (1999)) using rhodamine B isothiocyanate (Sigma) and chitosan. The labeling degree, determined by UV/VIS spectroscopy (HP 8452A diode array spectrophotometer, Hewlett Packard), was approximately one rhodamine group per 250 saccharide units.

\section{Preparation of the Self-Assembled PEMs.}

Solutions of HA, HA-Pac, chitosan (CH, HMW, degree of deacetylation: $85 \%$, Sigma) and $\mathrm{CH}-$ Rho in aqueous $\mathrm{NaCl}(0.14 \mathrm{M}, \mathrm{pH}$ 6, polymer concentration of $0.5 \mathrm{~g} / \mathrm{L})$ were prepared $\sim 2$ hours before preparation of the multilayers. A polyethyleneimine layer (PEI, MW 70,000, $5 \mathrm{~g} / \mathrm{L}$, Aldrich), used as a precursor layer to initiate the layer-by-layer self-assembly, was deposited onto the substrate (see below) and adsorption was allowed to proceed for $20 \mathrm{~min}$. The build up of the multilayer was accomplished by consecutive adsorption of oppositely charged polyelectrolytes, starting with HA, or HA-Pac. Adsorption of each polyelectrolyte was allowed to proceed for $5 \mathrm{~min}$. Excess polyelectrolyte was removed by rinsing the sample surface with an aqueous $\mathrm{NaCl}(0.14$ $\mathrm{M}, \mathrm{pH}$ 6) solution.

\section{Characterization.}

The self-assembly process was monitored with a dissipation enhanced quartz crystal microbalance (QCM-D, Q-Sense, Sweden) system using gold-coated QCM crystals from $Q$ sense. The substrates were cleaned with a piranha solution (concentrated $\mathrm{H}_{2} \mathrm{SO}_{4} / \mathrm{H}_{2} \mathrm{O}_{2}(30$ wt $\%$ in water) $=3 / 1 \mathrm{v} / \mathrm{v}$; Piranha solution is extremely energetic and should be handled with extreme caution) and pure water. Polyelectrolyte solutions were injected sequentially into the measurement cell and the frequency shifts were recorded continuously.

Atomic force microscopy imaging of paclitaxel loaded PEMs deposited onto silicon wafers was performed with a Nanoscope III (Digital Instruments, Santa Barbara, Ca) in the tapping mode. PEMs were built on silicon wafers as described above and dried with nitrogen flow. Areas of about $5 \times 5 \mu \mathrm{m}$ were scanned at a scan rate of $0.5 \mathrm{~Hz}$ (Figure S3)

Multilayers were built on quartz slides as described above and air-dried. The slides were mounted in the UV spectrometer sample holder and absorption spectra were registered, using an uncoated slide as a reference. 

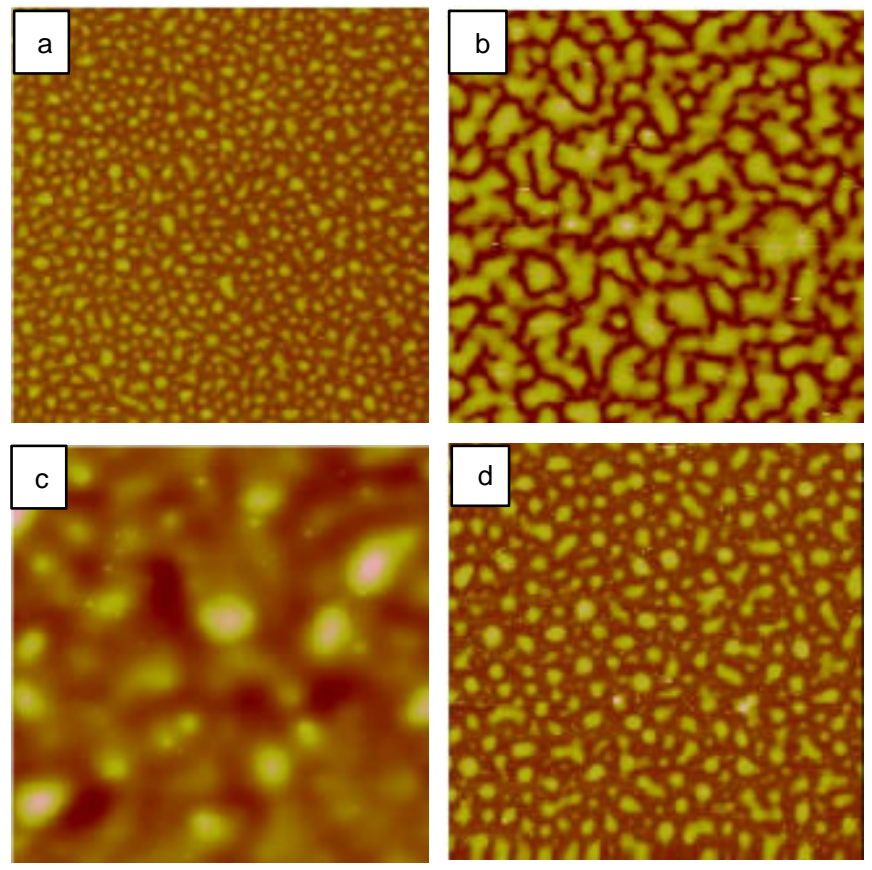

Figure S3. AFM height images of PEMs deposited on silicon wafers: (a) HA-Pac/(CH/HA-Pac) $)_{1}$, (b) $\mathrm{HA}-\mathrm{Pac} /(\mathrm{CH} / \mathrm{HA}-\mathrm{Pac})_{3}$ (c) $\mathrm{HA}-\mathrm{Pac} /(\mathrm{CH} / \mathrm{HA}-\mathrm{Pac})_{7}$ and (d) $\mathrm{HA} /(\mathrm{CH} / \mathrm{HA})_{3}$. The size of the images is $5 \times 5 \mu \mathrm{m}$ the maximum $Z$ scales are $40 \mathrm{~nm}$ for images (a), (b), and (d) and $100 \mathrm{~nm}$ for image (c).

\section{Cell viability assays.}

HA-Pac conjugate in solution. The cytotoxicity of HA-Pac was investigated by an in-vitro the cell proliferation assay. Murine macrophages $J 774$ were plated with a density of 50000 cells/well in a 24-wells plate and cultured in RPMI 1640 medium (Bio Media Canada, Drummondville, Quebec, Canada) supplemented with $5 \%$ fetal bovine serum, $100 \mathrm{U} / \mathrm{ml}$ penicillin, and $100 \mu \mathrm{g} / \mathrm{ml}$ streptomycin for $24 \mathrm{~h}$. A stock solution of HA-Pac $(0.5 \mathrm{~g} / \mathrm{L}$ in $0.14 \mathrm{M}$ aqueous $\mathrm{NaCl}$ was prepared. Cells were treated with increasing doses of HA-Pac, corresponding to paclitaxel doses of 0.1 $\mu \mathrm{g} / \mathrm{mL}, 1 \mu \mathrm{g} / \mathrm{mL}$, and $10 \mu \mathrm{g} / \mathrm{mL}$. Unmodified HA was used as control. Cells were cultured for 4 days and the cells viability was determined using MTT assays (Vybrant MTT Cell proliferation Assay, Molecular Probes). The results are presented in Figure S4. 


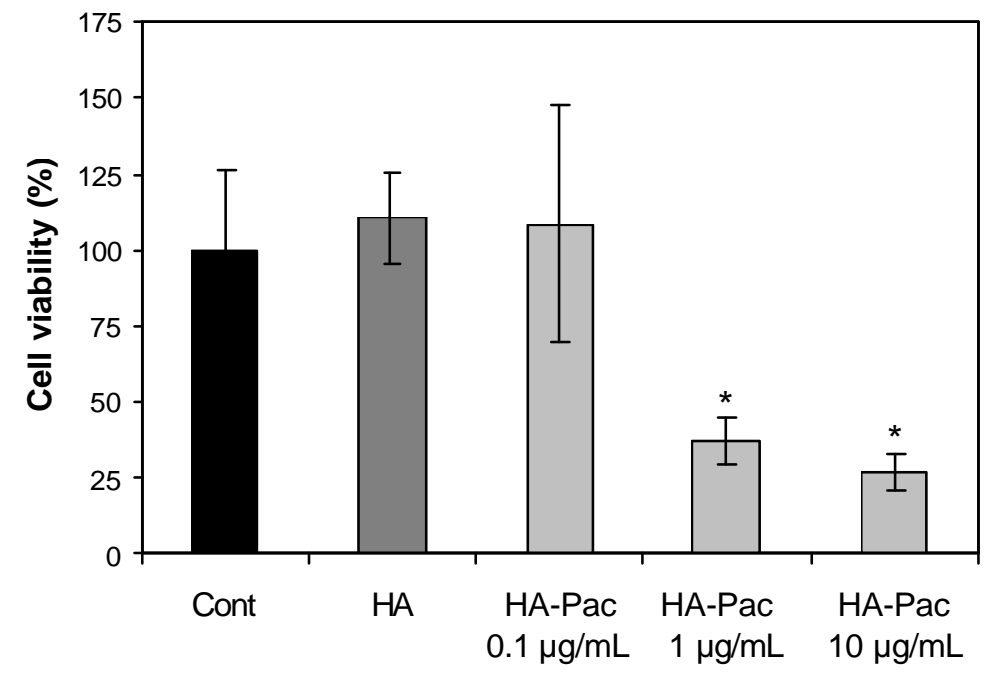

Figure S4. In vitro cytotoxicity of HA and HA-Pac with increasing loading of Paclitaxel: MTT assay with J774 macrophages. * $p<0.05$ Vs. control by ANOVA-Dunnett test;

HA-Pac loaded multilayers. 24-wells plates were treated with a PEI solution then they were coated with $(\mathrm{CH} / \mathrm{HA})_{10}$ or $(\mathrm{CH} / \mathrm{HA}-\mathrm{Pac})_{10}$ multilayers, starting and finishing with $\mathrm{HA}$, or $\mathrm{HA}-\mathrm{Pac}$, respectively. The coated plates were sterilized by UV light irradiation. Murine $\mathbf{J 7 7 4}$ macrophages were plated on the coated plates at a density of 50000 cells/well and allowed to grow for 4 days. Cell viability was determined using an MTT assay.

\section{Paclitaxel release studies.}

Cleaned 24-well plates were exposed to $\mathrm{PEI}$ and rinsed with $0.14 \mathrm{M} \mathrm{NaCl}$ prior to the assembly of 10 bilayers of $\mathrm{CH} / \mathrm{HA}(\mathrm{CH} / \mathrm{HA})_{10}, \mathrm{CH} / \mathrm{HA}-\mathrm{Pac}(\mathrm{CH} / \mathrm{HA}-\mathrm{Pac})_{10}$, and $\mathrm{CH}-\mathrm{Rho} / \mathrm{HA}-\mathrm{Pac}(\mathrm{CH}-$ Rho/HA-Pac) 10. In all multilayers, the uppermost layer was HA or HA-Pac. The multilayers were kept in contact with water $(0.25 \mathrm{~mL})$. At different times, the water was removed from the multilayer surface and kept aside. The films were kept for 20 min under acetonitrile $(0.75 \mathrm{~mL})$, which is a solvent for Pac, but a non-solvent for $\mathrm{HA}-\mathrm{Pac}, \mathrm{HA}$, and $\mathrm{CH}$. Next, the acetonitrile was carefully eliminated from the multilayer surface and added to the previously removed $0.25 \mathrm{~mL}$ of water. The UV/VIS absorption of the solution was recorded using water/acetonitrile $0.25 / 0.75 \mathrm{v} / \mathrm{v}$ as a reference solvent. This approach allows us to quantify the amount of Pac released from the multilayers and dissolved in water during the water treatment, as well as the amount of Pac which had been released from HA but remained embedded in the multilayers due to its low water solubility. Spectra registered for different times of contact between water and the multilayers are shown in Figure S5. The concentration of Paclitaxel released was monitored at $240 \mathrm{~nm}$ and the corresponding release curves are presented in Figure S6.

The stability of the multilayers during the release test was tested by treating under the same conditions rhodamine-labeled multilayers $(\mathrm{CH}-\mathrm{Rho} / \mathrm{HA}-\mathrm{Pac})_{10}$. The amount of Rrhodamine in the solution was measured, using the absorbance at $550 \mathrm{~nm}$, as a function of time (Figure S6). Negligible amount of rhodamine was detected (detection limit :ca. $1 \times 10^{-7} \mathrm{M}$ of Rho, i.e. ca. 0.6 $\mu \mathrm{g}$ of $\mathrm{Rho}-\mathrm{CH} / \mathrm{cm}^{2}$ ), indicating that the multilayers are stable and do not decompose under experimental conditions. 


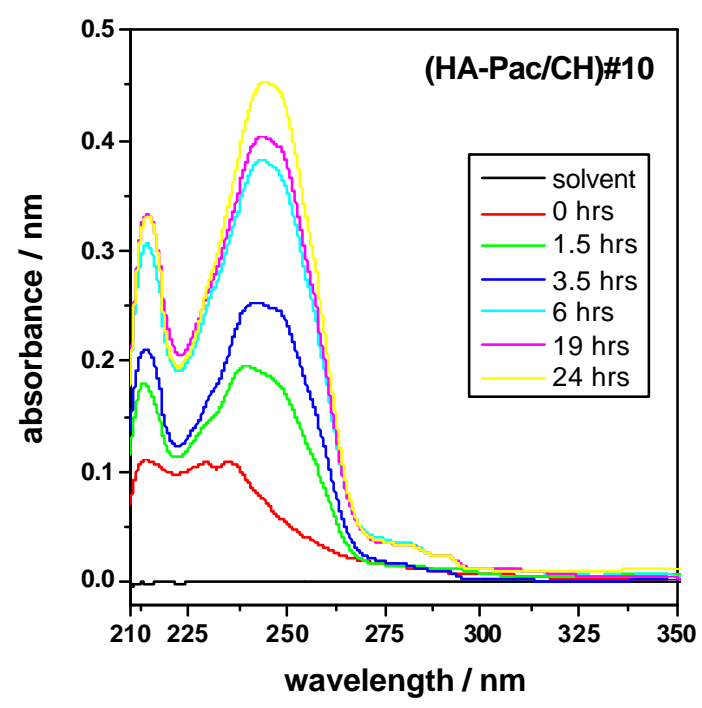

Figure S5. UV/VIS absorption spectra of acetonitrile/water $(0.75 / 0.25 \mathrm{v} / \mathrm{v})$ solutions after increasing times of contact with $(\mathrm{HA}-\mathrm{Pac} / \mathrm{CH})_{10}$ multilayers.

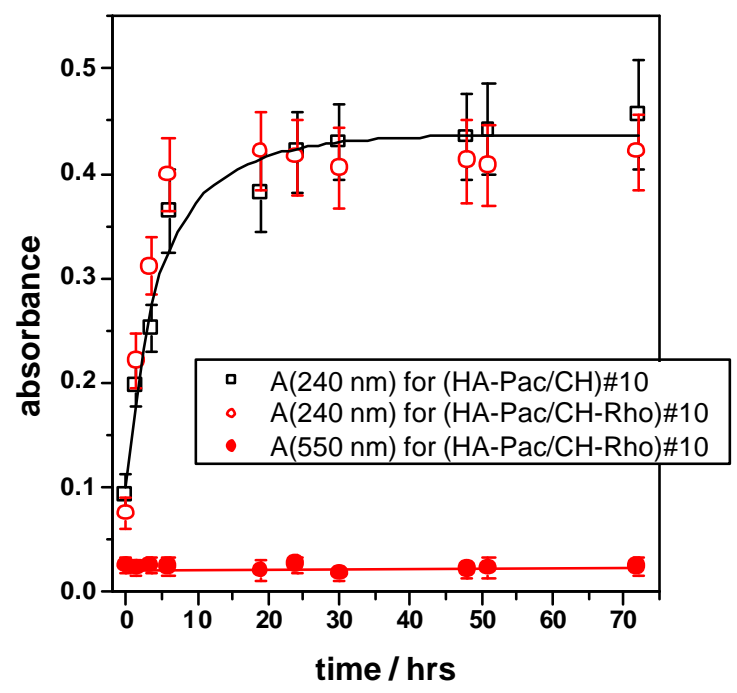

Figure S6. Release curves in water for paclitaxel (open symbols) and for rhodamine (filled symbols) from assemblies composed from 10 bilayers of $\mathrm{HA}-\mathrm{Pac} / \mathrm{CH}$ (squares) or $\mathrm{HA}-\mathrm{Pac} / \mathrm{CH}-$ Rho (circles). Each experiment was run in triplicate. 